\title{
Detection of Residual Levels and Associated Health Risk of Seven Pesticides in Fresh Eggplant and Tomato Samples from Narayanganj District, Bangladesh
}

\author{
Md. Nur Alam, ${ }^{1,2}$ M. Alamgir Zaman Chowdhury, ${ }^{1}$ \\ M. Sabir Hossain, ${ }^{2}$ Mohammad Mijanur Rahman, ${ }^{2}$ M. Abdur Rahman, \\ Siew Hua Gan, ${ }^{3}$ and Md. Ibrahim Khalil ${ }^{2,3}$ \\ ${ }^{1}$ Agrochemical and Environmental Research Division, Institute of Food and Radiation Biology, Atomic Energy Research Establishment, \\ Savar, Dhaka 1344, Bangladesh \\ ${ }^{2}$ Department of Biochemistry and Molecular Biology, Jahangirnagar University, Dhaka 1342, Bangladesh \\ ${ }^{3}$ Human Genome Centre, School of Medical Sciences, Universiti Sains Malaysia, 16150 Kubang Kerian, Kelantan, Malaysia \\ Correspondence should be addressed to Md. Ibrahim Khalil; drmikhalil@yahoo.com
}

Received 12 February 2015; Revised 29 June 2015; Accepted 1 July 2015

Academic Editor: Nivia Coelho

Copyright (C) $2015 \mathrm{Md}$. Nur Alam et al. This is an open access article distributed under the Creative Commons Attribution License, which permits unrestricted use, distribution, and reproduction in any medium, provided the original work is properly cited.

\begin{abstract}
Residual levels of seven frequently used pesticides were investigated in 140 samples of two common vegetables, eggplants and tomatoes, from agricultural fields in the Narayanganj district of Bangladesh. The analysis of pesticide residues was performed by high-performance liquid chromatography with photodiode array detection. A large percentage of the eggplants (50\%) and tomatoes (60\%) from the Narayanganj district were contaminated with pesticides, and all of the levels were above the maximum residual limit (MRL) proposed by the EC regulation. Diazinon was the most common (35\%) pesticide detected in the vegetable samples at a concentration of 45-450 times higher than the MRL. The health risk index for diazinon was highest for both eggplant and tomato samples, which may be due to its physiochemical properties. Fenitrothion and linuron are the two second most common types of pesticides detected in the vegetable samples. Regular monitoring of the use of common pesticides on vegetables should be conducted.
\end{abstract}

\section{Introduction}

The contamination of food by chemicals is a public health concern worldwide, and pesticides are a chemical hazard associated with food contamination [1]. Pesticide refers to any substance or mixture of substances in the food of humans or animals, including any specified derivatives such as degradation and conversion products, metabolites, reaction products, and impurities, of toxicological significance [2]. Pesticide residues cause both short- and long-term toxic effects that are hazardous to health, especially at higher levels that can lead to toxicity. Headaches, nausea, irritation, vomiting, diarrhea, abdominal pain, and hypersensitivity are repeatedly reported impacts of acute pesticide exposure. Additionally, chronic pesticide exposure increases the risk of reproductive defects, neurodegenerative disorders, organ damage (kidney/liver), mutagenic and carcinogenic transformation, and endocrine disruption [3-5]. Children are more susceptible due to their small body size, immature immune systems, and rapid growth cycles, especially in the brain and nervous systems [6].

Pesticide exposure is increasing in Bangladesh due to the acreage of irrigated agriculture. Approximately 80 types of registered pesticides with 170 different trade names are commonly used in agriculture and public health sectors in Bangladesh [7]. Of this number, organophosphates comprise $60.4 \%$, carbamates comprise $28.60 \%$, organochlorines comprise $7.60 \%$, and others comprise $3.4 \%$ of the total pesticides used [8]. The problem is compounded when the indiscriminate use of pesticides by farmers is made worse due to illiteracy and low levels of awareness of the hazardous effect of pesticides to human health $[8,9]$. 
Several studies have demonstrated that vegetables sprayed with pesticides will absorb them internally, which can create adverse effects [10-12] when they are consumed by humans and animals. Therefore, the identification and quantification of pesticides in food are of increasing public interest. However, in Bangladesh very little information is available on pesticide levels in vegetables [13], although they are consumed almost daily by the general public. In this study, we investigated the health risk and residue contamination levels of five organophosphates (diazinon, dimethoate, fenitrothion, parathion, and phosphamidon), one carbamate (carbofuran), and one phenyl urea herbicide (linuron) in two common vegetables (eggplant and tomato) collected from agricultural fields in the Narayanganj district of Bangladesh.

\section{Experiments}

2.1. Collection of Vegetable Samples. The vegetables were collected between June 2011 and December and March 2011 from the agricultural fields of three districts from Narayanganj (Rupgonj, Sonargaon, and Arihajar Upazilas), which are industrial areas located close to Dhaka City. Ten samples each of eggplants and tomatoes were collected directly from selected fields in the sampling area. The samples were placed in sterile polyethylene bags and transported to the laboratory on ice. They were stored at $4^{\circ} \mathrm{C}$ until analysis (within 24 hours).

2.2. Sample Preparation. Each vegetable sample (10 g) was homogenized with an Ultra-Turrax macerator (IKALabortechnik, Janke \& Kunkel GMBH \& CO.KG, Germany) at high speed for $3 \mathrm{~min}$ using a $40 \mathrm{~mL}$ solvent mixture that consisted of double-distilled hexane : acetone $(3: 1)$ at room temperature. Anhydrous sodium sulfate $(20.0 \mathrm{~g})$ was added to remove any remaining moisture. The samples were then centrifuged for $5 \mathrm{~min}$ at $3000 \mathrm{rpm}$, and the supernatant was transferred to a clean, graduated cylinder for volume measurement. The organic extract was concentrated to $5 \mathrm{~mL}$ on a vacuum rotary evaporator (Buchi, Switzerland) using a water bath at $45^{\circ} \mathrm{C}$ and 3.63 psi. The extract was cleaned up in a heat-activated $\left(150^{\circ} \mathrm{C}\right.$ for $\left.4 \mathrm{~h}\right)$ charcoal-silica gel-alumina $(0.1: 5.0: 5.0)$ column followed by elution with a solvent mixture of dichloromethane (2\%) in double-distilled hexane. The elute was concentrated to $1 \mathrm{~mL}$ in a rotary evaporator, followed by evaporation to dryness under a gentle nitrogen stream. The dried sample was reconstituted in acetonitrile $(1 \mathrm{~mL})$ prior to injection into high-performance liquid chromatography (HPLC).

2.3. Chromatographic Analysis. Analysis was conducted by a HPLC (Shimadzu, Japan) LC-10ADvp, equipped with an SPD-M 10 Avp attached to a photodiode array detector (Shimadzu SPD-M 10 Avp, 200-800 nm). A C18 Reverse Phase Alltech $(250 \times 4.6 \mathrm{~mm}, 5 \mu \mathrm{m})$ was used as the analytical column, and the column temperature was maintained at $30^{\circ} \mathrm{C}$. Acetonitrile in distilled water $(70: 30)$ was used as the mobile phase at a flow rate of $1.0 \mathrm{~mL} / \mathrm{min}$. Prior to HPLC analysis, the samples were filtered through $0.45 \mu \mathrm{m}$ nylon (Alltech
Associates, IL, USA) syringe filters. The chromatograms were obtained following manual injection $(20 \mu \mathrm{L})$ of both standard and sample solution (Figure 2). The suspected pesticides were identified based on the retention times of the respective standard pesticide preparation.

For preparation of the calibration curve, equal volumes of several different concentrations of standard solutions were injected into the HPLC machine. Quantification was performed according to the calibration method described by Bhattacharjee et al. [13]. Pesticide residue levels were determined by the following equation:

$$
R=\frac{\left(H_{A} \times V_{\mathrm{END}} \times W_{\mathrm{ST}}\right)}{\left(H_{\mathrm{ST}} \times V_{I} \times G\right)},
$$

where $R$ is $\mathrm{mg} / \mathrm{kg}$ for vegetable samples, $G$ is sample weight $(\mathrm{kg}), V_{\mathrm{END}}$ is terminal volume of the sample solution $(\mathrm{mL})$, $V_{I}$ is volume, $V_{\mathrm{END}}$ is volume injected into the $\operatorname{HPLC}(\mu \mathrm{L})$, $W_{\mathrm{ST}}$ is amount of standard pesticide injected with standard solvent $(\mu \mathrm{g}), H_{A}$ is peak area obtained from $V_{I}\left(\mathrm{~mm}^{2}\right)$, and $H_{\mathrm{ST}}$ is peak area obtained from $W_{\mathrm{ST}}\left(\mathrm{mm}^{2}\right)$.

\subsection{Chromatographic Method Validation Protocol and Evalua-} tion. The validation of the analytical method was performed according to the European Commission (EC) guidelines in terms of the accuracy, precision, and limit of quantification (LOQ) [14]. Accuracy was calculated by analyzing the samples of known concentration $(n=3)$ and comparing the estimated values with the actual values. Within our experimental limit, mean recovery for accuracy should be within 70$120 \%$. For accuracy experiments, tomato and eggplant (20 g) were utilized as matrix after homogenization and addition of appropriate amount of pesticides standards at two different fortification levels $(0.05$ and $0.50 \mu \mathrm{g} / \mathrm{mL})$. Control samples were processed along with spiked ones. Both sample and standard preparation were stood for one hour to permit equilibration. Equilibration was followed by extraction and cleanup process as described above. Percentage recovery was calculated by following equation:

$$
\text { Percentage recovery }=\left[\frac{\mathrm{CE}}{\mathrm{CM}} \times 100\right],
$$

where $\mathrm{CE}$ is the experimental concentration determined from the calibration curve and CM is the spiked concentration.

The precision was estimated by monitoring the repeated $(n=6)$ peak response and expressed by relative standard deviation (RSD). The acceptance criterion for precision is RSD $\leq 20 \%$. The LOQ was evaluated as signal-to-noise ratios of $10: 1$ and was obtained by analyzing unspiked samples $(n=10)$. LOQ must be lower than reporting limit and MRL with mean recoveries within $70-120 \%$ and $\mathrm{RSD} \leq$ $20 \%$.

The average percentage recoveries ranged from $80.33 \%$ to $99.00 \%$ while precision ranged from $3.14 \%$ to $13.25 \%$. In the present study, the LOQ was lower than reporting limit and MRL and ranged from 0.0036 to $0.0045 \mathrm{mg} / \mathrm{kg}$ for tomato and 0.0030 to 0.0037 for eggplant. 
2.5. Health Risk Index (HRI). The health risk indices associated with pesticide residues were estimated from food consumption. The health risk index was calculated by the following equation [15]:

$$
\text { HRI }=\left(\frac{\text { Estimated daily intake }}{\text { Acceptable daily intake }}\right) \text {. }
$$

The estimated daily intake was determined by multiplying the residual pesticide concentration $(\mathrm{mg} / \mathrm{kg})$ by the food consumption rate $(\mathrm{kg} /$ day) and dividing this number by a body weight of $60 \mathrm{~kg}$ for an average adult.

\section{Results and Discussion}

Large percentages of the eggplants (50\%) and tomatoes (60\%) were contaminated with pesticides (Table 1). This result is alarming because all of the contamination levels were above the maximum residual limit (MRL) proposed by the EC regulation [14].

The HRI in the eggplant samples was highest for diazinon eggplant, followed by dimethoate, phosphamidon, and fenitrothion (Table 2). The calculated HRI in eggplant for linuron eggplant was less than 1 , which is considered safe for human health [16].

The HRI in the tomato samples was also highest for diazinon (Table 3), followed by phosphamidon and carbofuran. The calculated HRIs for fenitrothion and linuron in the tomato samples were less than 1 and were therefore considered safe for human health [16].

Approximately $23.53 \%$ of the contaminated samples contained multiple residues. Overall, only fenitrothion contamination in both eggplants and tomatoes caused no health risk, as indicated by the HRI.

We investigated the pesticide residue contamination levels of five organophosphates (diazinon, dimethoate, fenitrothion, parathion, and phosphamidon), one carbamate (carbofuran), and one phenyl urea herbicide (linuron) in two common vegetables, eggplants and tomatoes, from agricultural fields in the Narayanganj district of Bangladesh. Large percentages of the eggplants (50\%) and tomatoes (60\%) were contaminated with pesticides at levels exceeding the maximum residual limit (MRL) set by the EC regulation.

None of the eggplant samples were contaminated with carbofuran. However, carbofuran was detected in a single tomato sample at a level 33 times above the MRL. The carbofuran level of market vegetables in Pakistan, including eggplants and tomatoes, has been recorded as 0.00 $0.39 \mathrm{mg} / \mathrm{kg}, 0.0-19.5$ times higher than the MRL $[17,18]$. However, the residual carbofuran level of market eggplant in Haryana, India, was within the MRL $(0.009-0.020 \mathrm{mg} / \mathrm{kg})$ [12].

Diazinon was the most common (35\%) pesticide detected in the vegetable samples (Figure 1). The highest concentration for diazinon was $4.514 \mathrm{mg} / \mathrm{kg}$ in an eggplant sample. This level is approximately 450 times higher than the MRL, which is alarming. The highest diazinon level detected in tomatoes was $3.612 \mathrm{mg} / \mathrm{kg}$, which is approximately 360 times higher than the MRL. This result is also alarming because tomatoes are

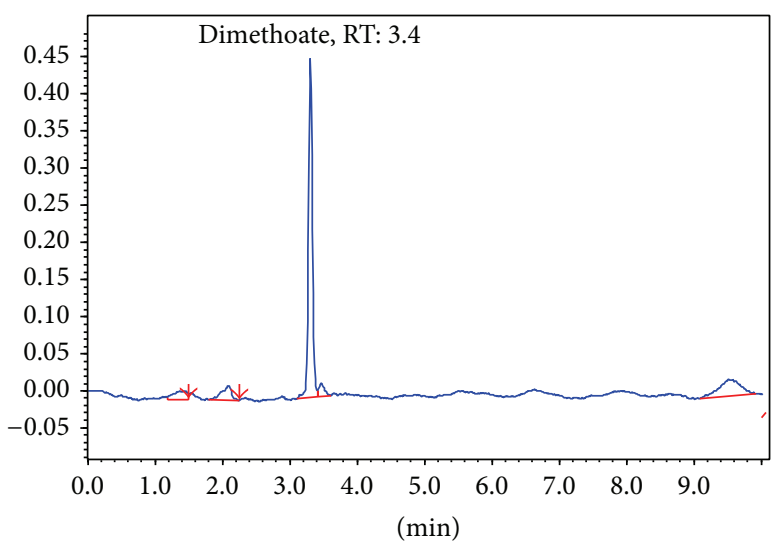

FIGURE 1: Typical chromatogram of a dimethoate standard ( $5 \mathrm{mg} / \mathrm{kg})$ (retention time $=3.4 \mathrm{~min}$ ).

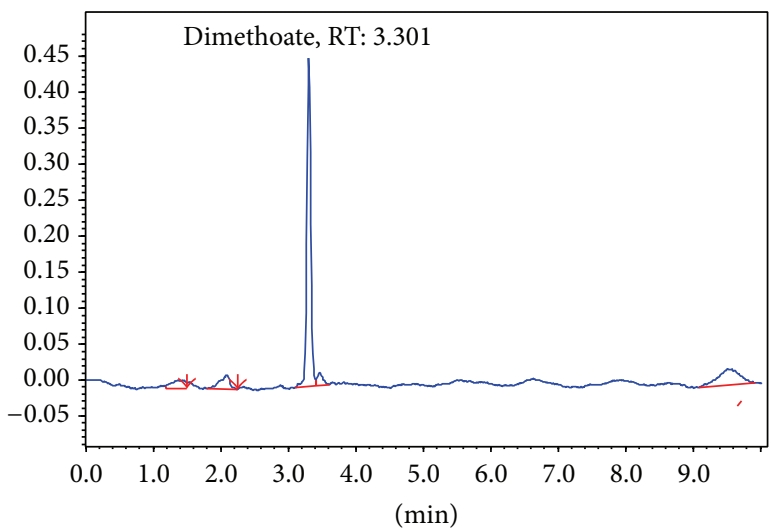

FIgURE 2: Chromatogram of VS-9 showing the presence of dimethoate (RT: $3.301 \mathrm{~min}$ ).

usually consumed raw in salads. The residual diazinon level of tomatoes was 10 times higher than the MRL in Spain and $0.0-1.3$ times higher than the MRL in Ghana $[19,20]$.

Dimethoate was detected in only a single eggplant sample at $1.806 \mathrm{mg} / \mathrm{kg}$ but was not found in the tomato samples. The detected level was 90 times higher than the MRL established by the European Union [15] but only 3.6 times higher than the MRL limit $(0.5 \mathrm{mg} / \mathrm{kg})$ set by the Codex Alimentarius Commission [21]. Bempah et al. reported a residual dimethoate level of $0.007-0.019 \mathrm{mg} / \mathrm{kg}$ in Ghanaian tomatoes [22], while the residual level in Indian eggplants was $0.001-0.002 \mathrm{mg} / \mathrm{kg}[12]$.

Fenitrothion and linuron are the next two most common types of pesticides detected in the vegetable samples after diazinon. The highest fenitrothion level $(1.88 \mathrm{mg} / \mathrm{kg})$ was detected in a tomato sample, which was approximately 188 times higher than the MRL. The highest linuron level in an eggplant sample $(1.07 \mathrm{mg} / \mathrm{kg})$ was approximately 21 times higher than the MRL. In India, the fenitrothion residual level for both tomato and eggplant was reported to exceed the MRL by 33 times [23]. In Ghana, the residual fenitrothion level of cabbage was also 16.50 times higher than the MRL set by the Codex Alimentarius Commission [24]. 
TABLE 1: Residual levels of carbofuran, diazinon, dimethoate, fenitrothion, linuron, parathion, and phosphamidon in eggplant and tomato samples.

\begin{tabular}{|c|c|c|c|c|c|c|c|}
\hline \multirow{2}{*}{ Sample } & \multicolumn{7}{|c|}{ Concentration (mg/kg) } \\
\hline & Carbofuran & Diazinon & Dimethoate & Fenitrothion & Linuron & Parathion & Phosphamidon \\
\hline Standard & 5 & 25 & 5 & 5 & 25 & 5 & 5 \\
\hline MRL & 0.020 & 0.010 & 0.020 & 0.010 & 0.050 & 0.050 & 0.010 \\
\hline B-1 & $\mathrm{BDL}$ & $0.453 \pm 0.033$ & BDL & BDL & BDL & BDL & $\mathrm{BDL}$ \\
\hline B-2 & $\mathrm{BDL}$ & BDL & BDL & $\mathrm{BDL}$ & BDL & $\mathrm{BDL}$ & BDL \\
\hline B-3 & $\mathrm{BDL}$ & $\mathrm{BDL}$ & $\mathrm{BDL}$ & $\mathrm{BDL}$ & BDL & $\mathrm{BDL}$ & $\mathrm{BDL}$ \\
\hline B-4 & BDL & $4.514 \pm 0.397$ & BDL & $\mathrm{BDL}$ & $1.073 \pm 0.054$ & BDL & $1.416 \pm 0.141$ \\
\hline B-5 & $\mathrm{BDL}$ & BDL & $\mathrm{BDL}$ & $\mathrm{BDL}$ & $0.657 \pm 0.059$ & $\mathrm{BDL}$ & BDL \\
\hline B-6 & $\mathrm{BDL}$ & $\mathrm{BDL}$ & $\mathrm{BDL}$ & $\mathrm{BDL}$ & BDL & BDL & BDL \\
\hline B-7 & $\mathrm{BDL}$ & $\mathrm{BDL}$ & $\mathrm{BDL}$ & $\mathrm{BDL}$ & $\mathrm{BDL}$ & $\mathrm{BDL}$ & $\mathrm{BDL}$ \\
\hline B-8 & $\mathrm{BDL}$ & $\mathrm{BDL}$ & BDL & $\mathrm{BDL}$ & $\mathrm{BDL}$ & $\mathrm{BDL}$ & $\mathrm{BDL}$ \\
\hline B-9 & $\mathrm{BDL}$ & $\mathrm{BDL}$ & $1.806 \pm 0.148$ & BDL & BDL & $\mathrm{BDL}$ & BDL \\
\hline B-10 & $\mathrm{BDL}$ & $\mathrm{BDL}$ & BDL & $0.674 \pm 0.038$ & $\mathrm{BDL}$ & $\mathrm{BDL}$ & BDL \\
\hline $\mathrm{T}-1$ & $\mathrm{BDL}$ & $1.888 \pm 0.204$ & $\mathrm{BDL}$ & BDL & BDL & $0.116 \pm 0.003$ & $\mathrm{BDL}$ \\
\hline $\mathrm{T}-2$ & $\mathrm{BDL}$ & $2.611 \pm 0.111$ & $\mathrm{BDL}$ & BDL & $\mathrm{BDL}$ & BDL & BDL \\
\hline $\mathrm{T}-3$ & BDL & ND & $\mathrm{BDL}$ & $\mathrm{BDL}$ & $\mathrm{BDL}$ & $\mathrm{BDL}$ & $\mathrm{BDL}$ \\
\hline $\mathrm{T}-4$ & $0.673 \pm 0.032$ & $3.451 \pm 0.417$ & BDL & $\mathrm{BDL}$ & BDL & BDL & BDL \\
\hline $\mathrm{T}-5$ & BDL & BDL & $\mathrm{BDL}$ & $0.657 \pm 0.059$ & $\mathrm{BDL}$ & $\mathrm{BDL}$ & BDL \\
\hline T-6 & $\mathrm{BDL}$ & $\mathrm{BDL}$ & BDL & BDL & BDL & $\mathrm{BDL}$ & $\mathrm{BDL}$ \\
\hline $\mathrm{T}-7$ & $\mathrm{BDL}$ & $\mathrm{BDL}$ & $\mathrm{BDL}$ & $\mathrm{BDL}$ & BDL & $\mathrm{BDL}$ & $\mathrm{BDL}$ \\
\hline $\mathrm{T}-8$ & $\mathrm{BDL}$ & $3.612 \pm 0.169$ & $\mathrm{BDL}$ & BDL & $0.540 \pm 0.020$ & $\mathrm{BDL}$ & $0.693 \pm 0.062$ \\
\hline T-9 & $\mathrm{BDL}$ & BDL & BDL & $1.888 \pm 0.204$ & BDL & BDL & BDL \\
\hline $\mathrm{T}-10$ & $\mathrm{BDL}$ & $\mathrm{BDL}$ & $\mathrm{BDL}$ & BDL & BDL & $\mathrm{BDL}$ & BDL \\
\hline
\end{tabular}

The results are expressed as the mean $\pm \mathrm{SD}$ (standard deviation) of triplicates measurements. Here, $\mathrm{B}=$ eggplant; $\mathrm{T}=$ tomato; $\mathrm{BDL}=$ below the detection limit $(0.001 \mathrm{ppm}) ; \mathrm{MRL}=$ maximum residual limit determined by EC regulation 396/2005 (from EU pesticide database) [15].

TABLE 2: Percentage contamination and HRI of the investigated pesticides for eggplant.

\begin{tabular}{lcccccc}
\hline Pesticide & Contamination rate $(\%)$ & MRL $(\mathrm{mg} / \mathrm{kg})$ & ADI $(\mathrm{mg} / \mathrm{kg} /$ day) & EDI $(\mathrm{mg} / \mathrm{kg} / \mathrm{day})$ & HRI & Health risk \\
\hline Carbofuran & 0 & 0.02 & 0.003 & - & - & - \\
Diazinon & 20 & 0.01 & 0.001 & 0.0143 & 14.3 & Yes \\
Dimethoate & 10 & 0.02 & 0.001 & 0.0104 & 10.4 \\
Fenitrothion & 10 & 0.01 & 0.002 & 0.0039 & 1.9 & Yes \\
Linuron & 20 & 0.05 & 0.010 & 0.0050 & 0.5 & No \\
Parathion & 0 & 0.05 & 0.005 & - & - \\
Phosphamidon & 10 & 0.01 & 0.001 & 0.0081 & 8.1 \\
\hline
\end{tabular}

MRL = maximum residual limit; $\mathrm{HRI}=$ human risk index; $\mathrm{ADI}=$ acceptable dietary intake; EDI = estimated dietary intake. The HRI was calculated by considering an average daily vegetable intake for a $60 \mathrm{~kg}$ adult as $0.345 \mathrm{~kg} /$ person/day $[16,36]$ and using the MRL determined by EC regulation $396 / 2005$ (from the EU pesticide database) [15].

TABLE 3: Percentage contamination and HRIs of the investigated pesticides for tomato.

\begin{tabular}{|c|c|c|c|c|c|c|}
\hline Pesticide & Contamination rate $(\%)$ & MRL (mg/kg) & ADI (mg/kg/day) & EDI (mg/kg/day) & HRI & Health risk \\
\hline Carbofuran & 10 & 0.02 & 0.003 & 0.0039 & 1.3 & Yes \\
\hline Diazinon & 40 & 0.01 & 0.001 & 0.0166 & 16.6 & Yes \\
\hline Dimethoate & 0 & 0.02 & 0.001 & - & - & - \\
\hline Fenitrothion & 20 & 0.01 & 0.002 & 0.0073 & 0.7 & No \\
\hline Linuron & 10 & 0.05 & 0.010 & 0.0031 & 0.3 & No \\
\hline Parathion & 10 & 0.05 & 0.005 & - & - & - \\
\hline Phosphamidon & 10 & 0.01 & 0.001 & 0.0040 & 4.0 & Yes \\
\hline
\end{tabular}

$\mathrm{MRL}=$ maximum residual limit; HRI = human risk index; $\mathrm{ADI}=$ acceptable dietary intake; EDI = estimated dietary intake. The HRI was calculated by considering an average daily vegetable intake for an adult $(60 \mathrm{~kg})$ as $0.345 \mathrm{~kg} /$ person/day $[15,16]$ and using the MRL determined by EC regulation $396 / 2005$ (from the EU pesticide database) [15]. 
TABle 4: Physiochemical properties of the investigated pesticides [37, 38].

\begin{tabular}{|c|c|c|c|c|}
\hline Name & Molecular formula & Molecular weight & Soil half-life (days) & Water solubility $(\mathrm{mg} / \mathrm{L})$ \\
\hline Carbofuran & $\mathrm{C}_{12} \mathrm{H}_{15} \mathrm{NO}_{3}$ & 221.30 & 50 & 351 \\
\hline Diazinon & $\mathrm{C}_{12} \mathrm{H}_{21} \mathrm{~N}_{2} \mathrm{O}_{3} \mathrm{PS}$ & 304.35 & 40 & 60 \\
\hline Dimethoate & $\mathrm{C}_{5} \mathrm{H}_{12} \mathrm{NO}_{3} \mathrm{PS}_{2}$ & 229.26 & 7 & 39,800 \\
\hline Fenitrothion & $\mathrm{C}_{9} \mathrm{H}_{12} \mathrm{NO}_{5} \mathrm{PS}$ & 277.24 & 4 & 30 \\
\hline Linuron & $\mathrm{C}_{9} \mathrm{H}_{10} \mathrm{Cl}_{2} \mathrm{~N}_{2} \mathrm{O}_{2}$ & 249.10 & 60 & 75 \\
\hline Parathion & $\mathrm{C}_{10} \mathrm{H}_{14} \mathrm{NO}_{5} \mathrm{PS}$ & 291.26 & 14 & 24 \\
\hline Phosphamidon & $\mathrm{C}_{5} \mathrm{H}_{12} \mathrm{NO}_{3} \mathrm{PS}_{2}$ & 229.26 & 17 & $1,000,000$ \\
\hline
\end{tabular}

Parathion was detected in only a single vegetable sample (tomato) at $0.116 \mathrm{mg} / \mathrm{kg}$, approximately 2.3 times higher than the MRL. A similar multiclass pesticide residue analysis showed that parathion levels in market eggplants and tomatoes in Bangladesh exceeded the MRL by $0-6.4$ and $0-4.6$ times, respectively [25]. In Rajasthan, India, the residual parathion level was 1.2-3.6 times higher than the MRL (0.06$0.18 \mathrm{mg} / \mathrm{kg}$ ) for tomatoes and 0-28.4 times higher than the MRL (0-1.42 mg/kg) for eggplants [26].

Phosphamidon was detected in a single sample for each of eggplant and tomato, with the highest level in an eggplant sample at $1.146 \mathrm{mg} / \mathrm{kg}$. This level is approximately 140 times higher than the MRL, which is alarming. In several field vegetables in India, the residual phosphamidon level exceeded the MRL $(0.51 \mathrm{mg} / \mathrm{kg})$ by 51.0 times [27].

Several factors may contribute to the high occurrence of pesticide residues detected in the vegetable samples from the Narayanganj district. Bangladesh frequently has a weak control mechanism, and rampant pesticide overdosing is practiced to increase crop productivity [28]. Furthermore, the majority of farmers lack sufficient perception and knowledge about the nature of chemical pesticides and their effects on health. Therefore, consumers may unknowingly use vegetables and fruits containing uncontrolled levels of pesticide residues $[8,9,29]$.

Fortunately, the soil degradation times of some pesticides, such as fenitrothion (4 days) and dimethoate (7 days), are relatively short, and it is possible that both pesticide levels would have dramatically decreased by the time the vegetable was consumed by the general public. This fact could also contribute to the relatively lower pesticide levels of these two types of pesticides seen in the analyzed samples. The differences in the soil half-life indicate that the natural decontamination of a pesticide also depends on its physiochemical properties. This may also explain the highest contamination seen with diazinon, which could actually be due to its relatively longer soil degradation time (40 days) and low water solubility $(60 \mathrm{mg} / \mathrm{L})$ (Table 4$)$. The water solubility of phosphamidon is very high, indicating that proper washing of vegetables before consumption may be crucial for its removal.

The HRI is the ratio of the estimated dietary intake (EDI) to the accepted daily intake (ADI) and indicates whether the calculated amount of the pesticide residue exceeds the amount of the pesticide that can be consumed every day for a lifetime. Thus, an HRI value greater than 1 indicates that the estimated dietary intake exceeds the ADI and is considered unsafe for human health [16]. The HRI for diazinon was the highest in both eggplant and tomato samples, which may be due to its physiochemical property.

Not only were the levels very high, but some of the vegetable samples also contained multiresidues of different types of pesticides. Exposure to pesticides through contaminated food leads to a spectrum of adverse health effects that depend on the nature of the pesticide and on the amount and duration of exposure [30]. Symptoms of exposure to organophosphates such as diazinon, dimethoate, fenitrothion, parathion, and phosphamidon include miosis, urination, diarrhea, diaphoresis, lacrimation, excitation, and salivation [31]. Anxiety, depression, coma, and convulsions are acute psychological and behavioral effects of organophosphorus pesticide exposure, while chronic exposure leads to cognitive and emotional deficits. Because organophosphates act directly on the nervous system by inhibiting the enzyme acetylcholinesterase (AChE) [32], severe organophosphate exposure is clinically manifested by marked miosis and loss of the pupillary light reflex, fasciculations, flaccid paralysis, pulmonary rales, respiratory distress, and cyanosis with less than $10 \%$ of the normal value of serum cholinesterase [33]. Exposure to carbofuran, an anticholinesterase carbamate, leads to overstimulation of the nervous system due to direct inhibition of acetylcholinesterase. Symptoms of carbofuran overexposure in humans include headache, weakness, abdominal cramping, nausea, blurred vision, convulsions, tremor, and coma [34]. Linuron exhibits relatively low acute toxicity but is classified as an unquantifiable Group $\mathrm{C}$ carcinogen and shows some evidence of developmental and reproductive toxicity. In low concentrations, linuron exposure antiandrogenically alters sexual differentiation [35].

This is a small pilot study that successfully pasteurized the residual pesticide levels of seven commonly used pesticides in two field vegetables before they were transported to market. The actual levels of exposure to consumers may thus be different after they reach their homes and following proper washing. More comprehensive studies should be undertaken to determine the levels of different pesticide residues on other vegetables and fruits originating from different regions in Bangladesh and at several different sampling intervals. Regular monitoring of the use of common pesticides on vegetables should also be undertaken as this study indicated the presence of high residual pesticide levels that may pose a health hazard. The adoption of effective legislation for properly regulating pesticide use and increasing awareness and technical know-how in the farming community should be incorporated in Bangladesh. 


\section{Conclusion}

Large percentages of the eggplants (50\%) and tomatoes $(60 \%)$ from the Narayanganj district were contaminated with pesticides, and all of the levels were above the MRL proposed by the EC regulation. Diazinon was the most common (35\%) pesticide detected in the vegetable samples. The HRI for diazinon was the highest for both eggplant and tomato samples, which may be due to its physiochemical property. Fenitrothion and linuron are the two second most common types of pesticides detected in the vegetable samples. Regular monitoring of the use of common pesticides on vegetables should be undertaken.

\section{Conflict of Interests}

The authors declare that there is no conflict of interests regarding the publication of this paper.

\section{Acknowledgment}

This study was financially supported by Universiti Sains Malaysia RU Grants (1001/PPSP/815073).

\section{References}

[1] A. Prüss-Ustün, C. Vickers, P. Haefliger, and R. Bertollini, "Knowns and unknowns on burden of disease due to chemicals: a systematic review," Environmental Health, vol. 10, article 9, 2011.

[2] A. D. McNaught and A. Wilkinson, IUPAC Compendium of Chemical Terminology, International Union of Pure and Applied Chemistry, 2000.

[3] W. J. Hayes and E. R. Laws, Handbook of Pesticide Toxicology, Academic Press, 1991.

[4] R. A. Bunggush and T. Anwar, "Preliminary survey for pesticide poisoning in Pakistan," Pakistan Journal of Biological Sciences, vol. 3, no. 111, pp. 1976-1978, 2000.

[5] H. Berrada, M. Fernández, M. J. Ruiz, J. C. Moltó, J. Mañes, and G. Font, "Surveillance of pesticide residues in fruits from Valencia during twenty months (2004/05)," Food Control, vol. 21, no. 1, pp. 36-44, 2010.

[6] B. Eskenazi, A. Bradman, and R. Castorina, "Exposures of children to organophosphate pesticides and their potential adverse health effects," Environmental Health Perspectives, vol. 107, no. 3, pp. 409-419, 1999.

[7] M. M. Rahman and S. I. Khan, "Food security in Bangladesh: food availability," in Food Security in Bangladesh, Paper Presented in the National Workshop on Food Security in Bangladesh, p. 07, Ministry of Food and Disaster Management, Government of the People's Republic of Bangladesh, and World Food Programme-Bangladesh, Dhaka, Bangladesh, 2005.

[8] S. Khan, M. Chowdhury, and M. Razzaque, "Chlorinated pesticide residue status in tomato, potato and carrot," Journal of Experimental Sciences, vol. 2, no. 1, pp. 1-5, 2011.

[9] M. A. Z. Chowdhury, S. Banik, B. Uddin, M. Moniruzzaman, N. Karim, and S. H. Gan, "Organophosphorus and carbamate pesticide residues detected in water samples collected from paddy and vegetable fields of the Savar and Dhamrai Upazilas in Bangladesh," International Journal of Environmental Research and Public Health, vol. 9, no. 9, pp. 3318-3329, 2012.
[10] N. Thanki, P. Joshi, and H. Joshi, "Effect of household processing on reduction of pesticide residues in Bringal (Eggplant, Solanum melongena)," Advances in Applied Science Research, vol. 3, no. 5, pp. 2860-2865, 2012.

[11] A. Ahmed, M. A. Randhawa, M. J. Yusuf, and N. Khalid, "Effect of processing on pesticide residues in food crops-a review," Journal of Agricultural Research, vol. 49, no. 3, pp. 379-390, 2011.

[12] B. Kumari, "Effects of household processing on reduction of pesticide residues in vegetables," ARPN Journal of Agricultural and Biological Science, vol. 3, no. 4, pp. 46-48, 2008.

[13] S. Bhattacharjee, A. N. M. Fakhruddin, M. A. Z. Chowdhury, M. A. Rahman, and M. K. Alam, "Monitoring of selected pesticides residue levels in water samples of paddy fields and removal of cypermethrin and chlorpyrifos residues from water using rice bran," Bulletin of Environmental Contamination and Toxicology, vol. 89, no. 2, pp. 348-353, 2012.

[14] DG SANCO, "Method validation and quality control procedures for pesticide residues analysis in food and feed," Document SANCO/10684/2009, 2010, http://www.crl-pesticides.eu/ library/docs/allcrl/AqcGuidance_Sanco_2009_10684.pdf.

[15] EU Pesticide Database, Maximum Residue Level as determined by EC regulation 396/2005, 2005, http://ec.europa.eu/food/ plant/pesticides/legislation/max_residue_levels_en.htm.

[16] X. Wang, T. Sato, B. Xing, and S. Tao, "Health risks of heavy metals to the general public in Tianjin, China via consumption of vegetables and fish," Science of the Total Environment, vol. 350, no. 1-3, pp. 28-37, 2005.

[17] M. F. Iqbal, U. Maqbool, I. Perveez, M. Farooq, and M. R. Asi, "Monitoring of insecticide residues in brinjal collected from market of Noshera Virkan, Pakistan," Journal of Animal and Plant Sciences, vol. 19, no. 2, pp. 90-93, 2009.

[18] Y. Latif, S. T. H. Sherazi, and M. I. Bhanger, "Assessment of pesticide residues in commonly used vegetables in Hyderabad, Pakistan," Ecotoxicology and Environmental Safety, vol. 74, no. 8, pp. 2299-2303, 2011.

[19] C. K. Bempah, J. Asomaning, and J. Boateng, "Market basket survey for some pesticides residues in fruits and vegetables from Ghana," Journal of Microbiology, Biotechnology and Food Sciences, vol. 2, no. 3, pp. 850-871, 2012.

[20] J. Fenoll, P. Hellín, C. M. Martínez, M. Miguel, and P. Flores, "Multiresidue method for analysis of pesticides in pepper and tomato by gas chromatography with nitrogen-phosphorus detection," Food Chemistry, vol. 105, no. 2, pp. 711-719, 2007.

[21] FAO/WHO (Food and Agriculture Organization/World Health Organization), "Food standards programme," in Proccedings of the Codex Alimentarius Commission 27th Session, pp. 1-103, Geneva, Switzerland, June-July 2004.

[22] C. K. Bempah, J. Asomaning, D. A. Ansong, J. Boateng, and S. B. Asabere, "Contamination levels of selected organochlorine and organophosphorou pesticides in Ghanaian fruits and vegetables," Emirates Journal of Food and Agriculture, vol. 24, no. 4, pp. 293-301, 2012.

[23] G. Satpathy, Y. K. Tyagi, and R. K. Gupta, "Removal of organophosphorus (OP) pesticide residues from vegetables using washing solutions and boiling," Journal of Agricultural Science, vol. 4, no. 2, p. 69, 2011.

[24] F. A. Armah, "Assessment of pesticide residues in vegetables at the farm gate: cabbage (Brassica oleracea) cultivation in Cape Coast, Ghana," Research Journal of Environmental Toxicology, vol. 5, no. 3, pp. 180-202, 2011.

[25] M. S. Hossain, M. A. Hossain, M. A. Rahman, M. M. Islam, M. A. Rahman, and T. M. Adyel, "Health risk assessment of 
pesticide residues via dietary intake of market vegetables from Dhaka, Bangladesh," Foods, vol. 2, no. 1, pp. 64-75, 2013.

[26] P. Charan, S. Ali, K. Yati, and K. Sharma, "Monitoring of pesticide residues in farmgate vegetables of central Aravalli region of western India," American-Eurasian Journal of Agricultural \& Environmental Science, vol. 7, no. 3, pp. 255-258, 2010.

[27] V. S. Shirashyad and M. B. Kanade, "Pesticide residues in vegetable plants guar and onion," DAV International Journal of Science, vol. 1, no. 1, pp. 42-43, 2012.

[28] M. Rahman and M. Alam, "Risk assessment of pesticides used in Bangladesh," Journal of Civil Engineering, vol. 25, no. 1, pp. 97-106, 1997.

[29] A. Z. Chowdhury, S. A. Jahan, M. N. Islam et al., "Occurrence of organophosphorus and carbamate pesticide residues in surface water samples from the Rangpur district of Bangladesh," Bulletin of Environmental Contamination and Toxicology, vol. 89, no. 1, pp. 202-207, 2012.

[30] R. C. Gupta, "Carbofuran toxicity, Journal of Toxicology and Environmental Health, vol. 43, no. 4, pp. 383-418, 1994.

[31] P. C. F. Moore, Children and Pollution: Why Scientists Disagree: Why Scientists Disagree, Oxford University Press, Oxford, UK, 2009.

[32] J. Mearns, J. Dunn, and P. R. Lees-Haley, "Psychological effects of organophosphate pesticides: a review and call for research by psychologists," Journal of Clinical Psychology, vol. 50, no. 2, pp. 286-294, 1994.

[33] S. V. Kumar, M. Fareedullah, Y. Sudhakar, B. Venkateswarlu, and E. A. Kumar, "Current review on organophosphorus poisoning," Archives of Applied Science Research, vol. 2, no. 4, pp. 199-215, 2010.

[34] D. Tenenbaum, "Pesticides: carbofuran under review," Environmental Health Perspectives, vol. 116, no. 10, article A425, 2008.

[35] C. Lambright, J. Ostby, K. Bobseine et al., "Cellular and molecular mechanisms of action of linuron: an antiandrogenic herbicide that produces reproductive malformations in male rats," Toxicological Sciences, vol. 56, no. 2, pp. 389-399, 2000.

[36] G. Darko and O. Akoto, "Dietary intake of organophosphorus pesticide residues through vegetables from Kumasi, Ghana," Food and Chemical Toxicology, vol. 46, no. 12, pp. 3703-3706, 2008.

[37] Hazardous Substances Data Bank (HSDB), "Comprehensive, peer-reviewed toxicology data for about 5,000 chemicals," http://toxnet.nlm.nih.gov/cgi-bin/sis/htmlgen?HSDB.

[38] OSU Extension Pesticide Properties Database, National Pesticide Information Center, http://npic.orst.edu/ingred/ppdmove .htm. 

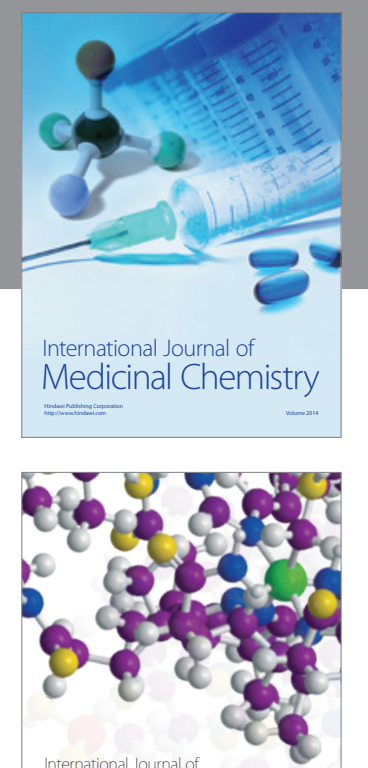

\section{Carbohydrate} Chemistry

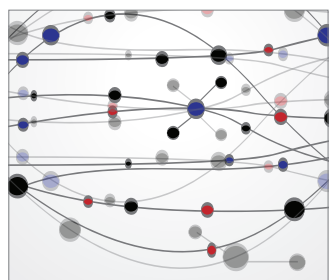

The Scientific World Journal
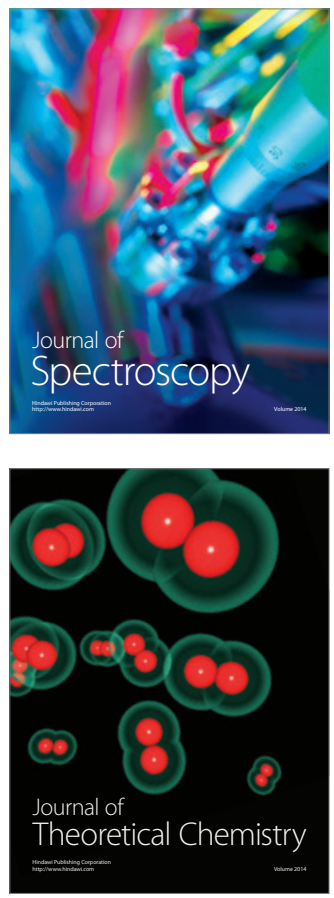
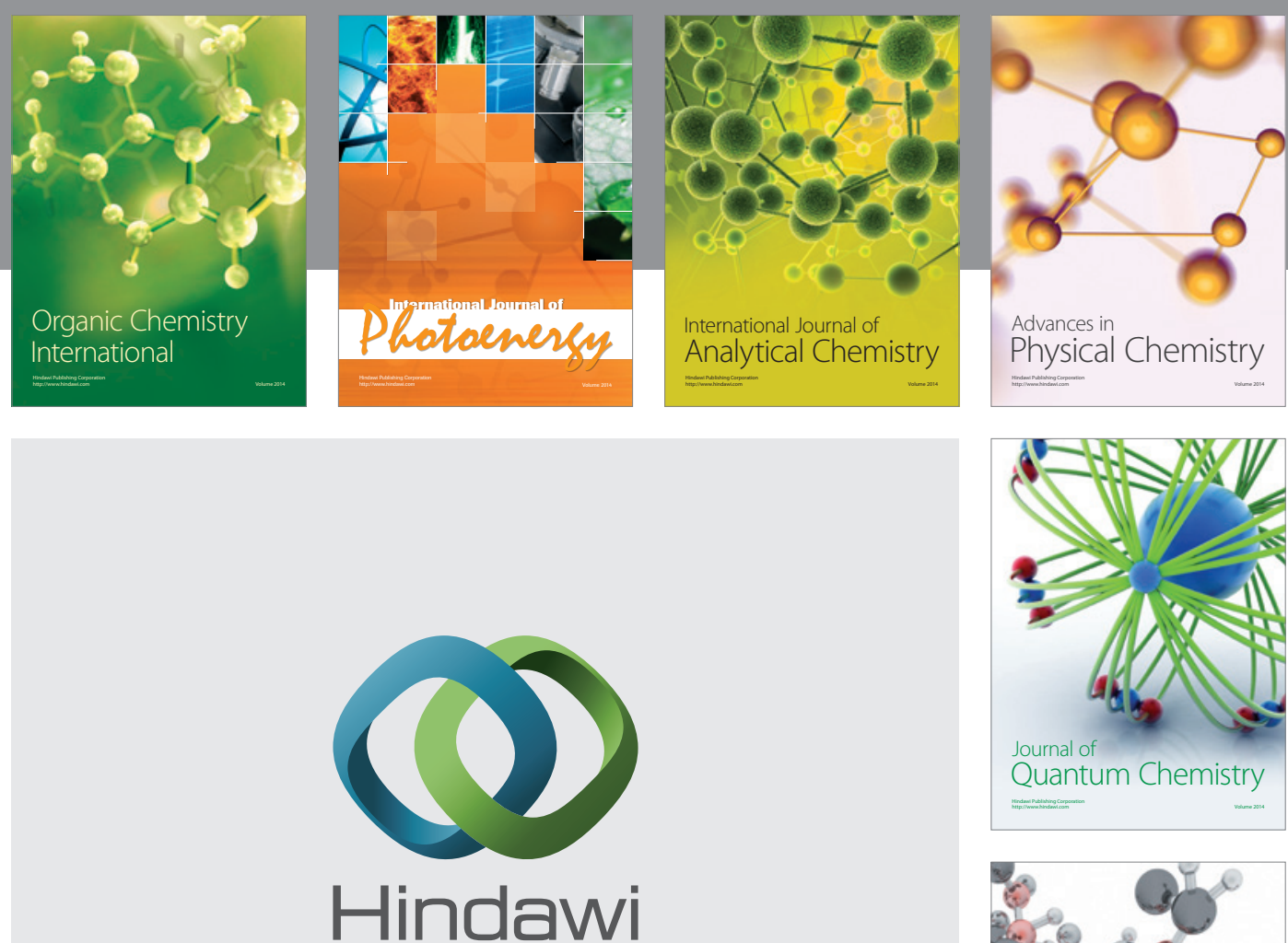

Submit your manuscripts at

http://www.hindawi.com

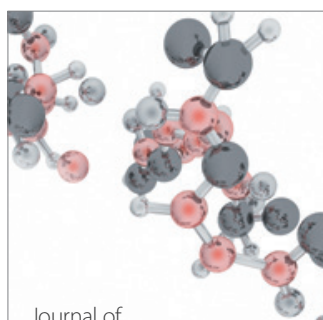

Analytical Methods

in Chemistry

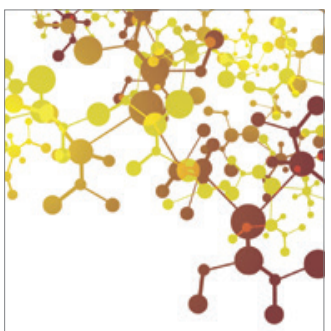

Journal of

Applied Chemistry

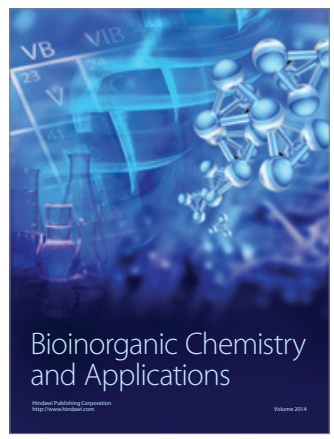

Inorganic Chemistry
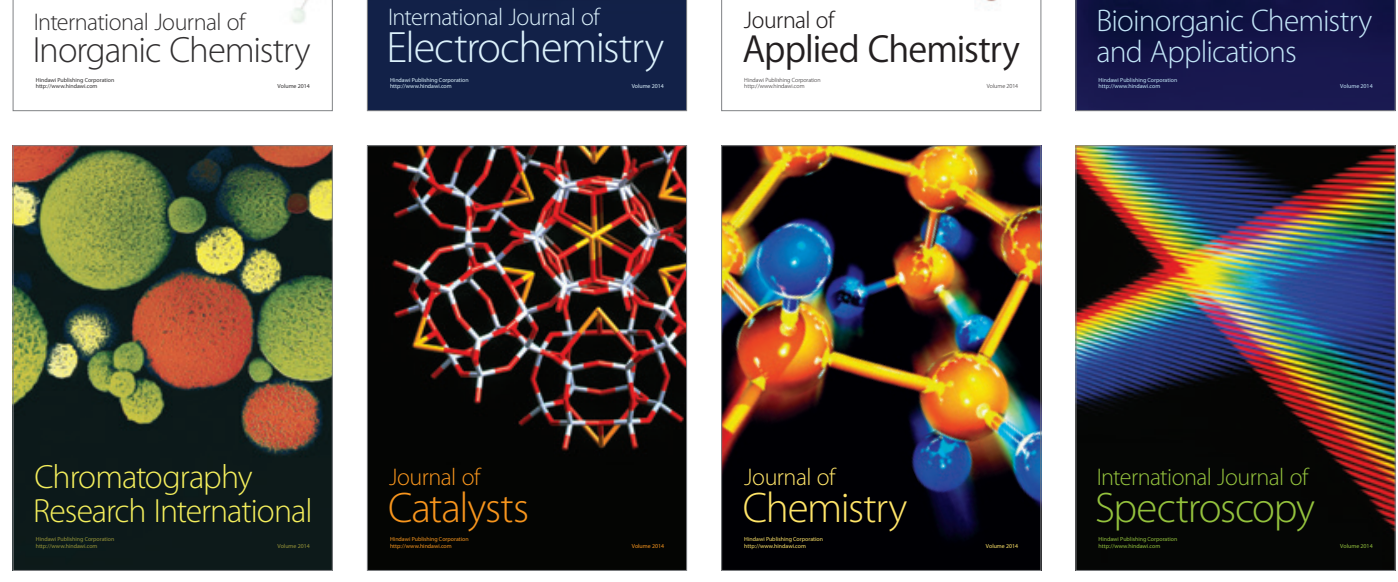